\title{
Higher blood pressure in elderly hypertensive females, with increased arterial stiffness and blood pressure in females with the Fibrillin-1 2/3 genotype
}

Ida Åström Malm", Urban Alehagen², Peter Blomstrand ${ }^{1,3}$, Ulf Dahlström²,4 and Rachel De Basso ${ }^{1}$

\begin{abstract}
Background: Elderly patients have a relatively high cardiovascular risk due to increased arterial stiffness, elevated blood pressure and decreased amounts of elastin in the arteries. The composition of the media layer in the arterial wall, comprising elastin, collagen, smooth muscle cells, proteoglycans, fibronectin and fibrillin-1, influences its mechanical properties. Mutations in the fibrillin-1 gene leads to increased aortic stiffness, elevated pulse pressure and aortic root dilatation. This study investigates whether there is a sex difference among hypertensive elderly patients regarding blood pressure, arterial stiffness and fibrillin-1 genotypes.
\end{abstract}

Methods: A total of 315 hypertensive subjects (systolic blood pressure $>140 \mathrm{mmHg}$ ) were included in this study (155 men and 160 women aged 71-88 years). Aortic pulse wave velocity and augmentation index were determined using SphygmoCor, and brachial blood pressure was measured using an oscillometric technique. Fibrillin-1 was genotyped by polymerase chain reaction and with a capillary electrophoresis system.

Results: Females showed a significantly higher peripheral mean arterial pressure (females; $107.20 \mathrm{mmHg}$, males $101.6 \mathrm{mmHg}, p=0.008$ ), central mean arterial pressure (females; $107.2 \mathrm{mmHg}$, males $101.6 \mathrm{mmHg} p=0.008$ ), central systolic blood pressure (females; $148.1 \mathrm{mmHg}$, males $139.2 \mathrm{mmHg}, p<0.001$ ) and central pulse pressure (females; $68.9 \mathrm{mmHg}$, males $61.6 \mathrm{mmHg}, p=0.035)$ than males. Females with the Fibrillin-1 2/3 genotype showed a significantly higher augmentation index (FBN1 2/3; 39.9\%, FBN1 2/2 35.0\%, FBN1 2/4 35.8, $p=0.029$ ) and systolic blood pressure (FBN1 2/3; $174.6 \mathrm{mmHg}$, FBN1 2/2168.9 mmHg, FBN1 2/4169.9 mmHg, $p=0.025$ ) than females with the $2 / 2$ and $2 / 4$ genotypes.

Conclusion: The findings of this study may indicate that hypertensive elderly females, especially elderly females with Fibrillin-1 2/3, have increased systolic blood pressure and arterial stiffness.

Keywords: Arterial stiffness, Elderly, Female, Fibrillin-1, Hypertension

\footnotetext{
* Correspondence: Ida.astrom-malm@ju.se

'School of Health and Welfare, Jönköping University, Jönköping, Sweden

Full list of author information is available at the end of the article
}

(c) The Author(s). 2020 Open Access This article is licensed under a Creative Commons Attribution 4.0 International License, which permits use, sharing, adaptation, distribution and reproduction in any medium or format, as long as you give appropriate credit to the original author(s) and the source, provide a link to the Creative Commons licence, and indicate if changes were made. The images or other third party material in this article are included in the article's Creative Commons licence, unless indicated otherwise in a credit line to the material. If material is not included in the article's Creative Commons licence and your intended use is not permitted by statutory regulation or exceeds the permitted use, you will need to obtain permission directly from the copyright holder. To view a copy of this licence, visit http://creativecommons.org/licenses/by/4.0/ The Creative Commons Public Domain Dedication waiver (http://creativecommons.org/publicdomain/zero/1.0/) applies to the data made available in this article, unless otherwise stated in a credit line to the data. 


\section{Background}

It is still unclear whether arterial wall stiffness is a cause or a consequence of high blood pressure but the two conditions are close associated to each other [1]. Increased resistance in the small arteries enhance mean blood pressure which increase arterial wall stiffness and pulse wave velocity in the large elastic arteries. This raises central blood pressure further which might lead to organ injuries and damage to the small resistance vessels. Hypertension is a common disease among elderly individuals and is an increasing public health concern [2]. Thus, it is important to identify new potential biomarkers to detect preclinical disease and prevent hypertension. Arterial wall stiffness is an independent predictor of cardiovascular morbidity and mortality, increasing with age and is observed among elderly [3, 4]. An increased arterial stiffness and pulse wave velocity (PWV) cause an early return of the reflected pulse wave in late systole, which increases the central pulse pressure, myocardial oxygen demand and left ventricular workload. Some clinical manifestations of decreased arterial distensibility are hypertension and elevated pulse pressure (PP) [5].

Similar to arterial stiffness, systolic blood pressure (SBP) increases with age [6]. Elderly patients have a higher cardiovascular risk, through increased arterial wall stiffness, elevated blood pressure and decreased levels of elastin in their large elastic arteries [7-9]. Males have a higher SBP than females throughout most of their lives; however, after 65 years of age, the difference between sexes seems to disappear, and after the age of 70, females may have a higher prevalence of hypertension [10-12]. Thus, it is of interest to study the differences in the mechanical properties of arteries between the sexes among elderly patients with high SBP.

Mutations in the fibrillin-1 (FBN1) gene is associated with increased aortic stiffness, elevated PP and aortic root dilatation [13, 14]. Several studies have found an association between the FBN1 2/3 genotype and arterial stiffness in males. Medley et al. (2002) and Powell et al. (1996) reported a relationship between the $2 / 3$ genotype and an increased PP $[15,16]$, and in a later study an association between the $2 / 3$ genotype and an increased heart rate (HR), blood pressure and abdominal aortic stiffness in apparently healthy first-degree male relatives of patients with abdominal aortic aneurysms (AAAs) was reported [17]. In a study of both sexes, no associations between the FBN1 2/3 genotype and increased aortic PWV were observed [18]. The aim of this study was to investigate whether there is a sex difference regarding blood pressure, arterial stiffness and the FBN1 genotypes in an elderly hypertensive population.

\section{Methods}

\section{Study population}

The study population was recruited from an ongoing longitudinal study of elderly community-living people from a rural municipality of southeast Sweden. Inhabitants aged 65-82 years were invited to join the original study between 1998 and 2001. A total of 1130 individuals were invited, and 876 of these individuals agreed to participate in the study [19]. In a follow-up study, from 2003 to 2005, a cross-sectional study with the same population was performed. Before the follow-up study started, 123 study subjects had died. Of the remaining 753 subjects, 452 subjects agreed to participate in the current study. Twenty-three subjects were excluded because of irregular HR with variable PP in the arteries, hepatitis infection or difficulties obtaining blood samples. Among the remaining 429 subjects, the abdominal aorta was examined using ultrasound. After the ultrasound examination, an additional 23 subjects were excluded due to low-quality ultrasonic measurements [20]. In this study, we investigated subjects with SBP $>140$ $\mathrm{mmHg}$, and the final study population was 315 subjects (155 men and 160 women) within the age group of 7188 years $[20,21]$.

The subjects were instructed not to use tobacco or consume coffee or tea for at least $4 \mathrm{~h}$ prior to their examinations. In addition, the participants had a physical examination and were asked about cardiovascular risk factors, cardiovascular diseases and medications. Subjects with previously diagnosed hypertension or with an $\mathrm{SBP} \geq 140 \mathrm{mmHg}$ were defined as hypertensive. Diabetes mellitus was defined as a previous diagnosis of diabetes mellitus or with $\geq 7 \mathrm{mmol}^{-1}$ fasting plasma glucose. Ischemic heart disease was defined as a previous diagnosis of ischemic heart disease confirmed by exercise ECG or coronary angiography or electrocardiographically (ECG) verified myocardial infarction. Subjects who reported that they smoked were classified as smokers. Height and weight were measured and used for calculation of body mass index (BMI). All subjects in the study gave their written informed consent [20, 21]. The study was approved by the Regional Ethical Review board in Linköping, Sweden, and was conducted in accordance with the principles stated in the Declaration of Helsinki.

\section{Measurements}

All measurements were performed under standardized conditions. Brachial blood pressure was measured after at least $15 \mathrm{~min}$ of rest when the subject was in the supine position using an oscillometric technique (Dinamap model PRO 200 Monitor, Critikon, Tampa, FL, USA). Systolic, diastolic and mean arterial pressures were measured [20, 21]. 
The ankle brachial pressure index (ABPI) was calculated using the SBP measured from the dorsalis pedis and the posterior tibial arteries recorded by a hand-held $8 \mathrm{MHz}$ Doppler probe and a 12-cm standard cuff divided by the brachial systolic pressures measured in the right and left arm [20, 21].

Radial artery pulse waves were obtained noninvasively using the SphygmoCor system (version 7.0, Model MM3, AtCor Medical, Sydney, Australia). The SphygmoCor system was equipped with a Millar pressure tonometer. For PWV, the central pressure waveform was derived using a generalized transfer function, calculated from an 11-s recording of the radial artery pressure. For calibration of the pressure wave, brachial systolic and diastolic blood pressure were used. Blood pressure was measured before the pulse wave recordings. Registrations of pulse waves were repeated at least three times, and average data from the three most successful registrations were used for analysis. Only good-quality recordings were used for pulse wave analysis (PWA). The augmentation index (AIx) and pressure augmentation (AG) were calculated from the central pressure waveform. AIx is the pressure augmentation expressed as the percentage of the central pulse pressure $(\mathrm{cPP}): \mathrm{AIx}=($ AG/PP) $\times 100[20,21]$.

\section{Blood samples}

Blood samples were taken after overnight fasting and collected in prechilled plastic Vacutainer tubes (Terumo EDTA K-3). Plasma was prepared by centrifugation at $3000 \mathrm{~g}$ for $10 \mathrm{~min}$ at $4{ }^{\circ} \mathrm{C}$. Blood and plasma were stored at $-70^{\circ} \mathrm{C}$ pending analysis. Plasma levels of fasting glucose, low-density lipoprotein (LDL) and high-density lipoprotein (HDL) were measured [20, 21].

\section{FBN1 genotyping}

FBN1 genotyping was performed in 2009, and the investigators performing these assays were blinded to the results of the vascular testing. DNA was prepared for polymerase chain reaction (PCR) by typing the variable tandem nucleotide repeat (VNTR) (TAAAA) $)_{\mathrm{n}}$ in intron 28 of the FBN1 gene on chromosome 15 using the forward primer 5' 6FAM - CAG AGT ACA TAG AGT GTT TTA GGG AGA - 3' and the reverse primer $5^{\prime}$ GTT TCT TCC TGG CTA CCA TCC AAC TCC c-3'. PCR was performed in a volume of $12 \mu \mathrm{l}$ with predenaturation at $95^{\circ} \mathrm{C}$ for $9 \mathrm{~min} ; 35$ cycles of denaturation for $30 \mathrm{~s}$, annealing at $65^{\circ} \mathrm{C}$ for $30 \mathrm{~s}$ ( 35 cycles), and extension at $72{ }^{\circ} \mathrm{C}$ for $30 \mathrm{~s}$ ( 35 cycles); and a final extension at $72{ }^{\circ} \mathrm{C}$. A $1-\mu \mathrm{l}$ portion of the PCR product was diluted with $9 \mu$ of highly deionized formamide (GENESCAN ${ }^{\mathrm{sm}}$ $500 \mathrm{ROX}^{\mathrm{m}}$ Size Standard) for electrokinetic injection on the capillary electrophoresis system. The DNA fragments were labeled with the $\mathrm{ROX}^{\mathrm{m}}$ fluorophore. The labeling results in a single peak under denaturing conditions were obtained, and the alleles were then identified by the number of base pairs (bp) comparable to each peak (2/2: $162 \mathrm{bp}, 162 \mathrm{bp} ; 2 / 3$ : $157 \mathrm{bp}, 162 \mathrm{bp}$; and 2/4: 152 bp, 162 bp) [20-22].

\section{Statistics}

All data are presented as the means \pm SDs. All continuous variables were checked for normality distribution, a logtransformation was used in continuous variables with a non-normality distribution. Student's t-test and MannWhitney U-test were used to calculate differences between sexes. One-way ANOVA with post hoc testing was used to compare the differences between the genotypes. Variance analysis was used to adjust the dependent variables (peripheral mean arterial pressure (pMAP), central mean arterial pressure (cMAP), central SBP (cSBP) and cPP for age, body surface area (BSA) and HR). $p$-values $<0.05$ were considered statistically significant. The statistical analyses were performed with IBM SPSS 25.0.

\section{Results \\ Demographic data}

A total of 315 hypertensive subjects (155 males/160 females; mean age, $78 \pm 3.4$ years) were analyzed, and demographic data according to sex are presented in Table 1. There were no significant differences between sexes regarding age, BMI, CRP, glucose, diabetes, hyperlipidemia or angina pectoris. Male subjects had a higher frequency of smokers $(p=0.005)$ and higher creatinine $(p<0.001)$ than female subjects, whereas females had higher HDL $(p<0.001)$ and LDL $(p=0.048)$ than males. Males were more affected by myocardial infarction $(p=$ 0.021) than females. However, regarding heredity for cardiovascular disease, females showed increased family history of CV $(p=0.026)$ compared to males. Furthermore, there were no significant differences between males and females regarding treatments with statins, beta receptor blockers and ACE inhibitors. However, females were more commonly treated with diuretics than males $(p=0.045)$.

\section{Blood pressure and arterial stiffness}

Data on pressure and arterial stiffness divided by sex are presented in Table 2. When the SphygmoCor technique was used, the data showed that females had significantly higher pMAP $(p=0.008)$ and $\operatorname{cMAP}(p=0.008)$ than males. These sex differences were also observed for cSBP $(p<0.001)$ and cPP $(p=0.035)$. After adjustments for age, HR and BSA, these differences were strengthened (pMAP $p=0.005$; cMAP $p=0.005$; $\operatorname{cSBP} p=0.001$; $\mathrm{cPP}$ $p<0.001)$. Differences regarding AIx $(p<0.001)$, AG $(p<0.001)$ and transit time (TR) $(p<0.001)$ arterial stiffness were observed between sexes. 
Table 1 Characteristics according to sex

\begin{tabular}{|c|c|c|c|c|}
\hline & $\begin{array}{l}\text { All } \\
n=315\end{array}$ & $\begin{array}{l}\text { Male } \\
n=155\end{array}$ & $\begin{array}{l}\text { Female } \\
n=160\end{array}$ & $p$-value \\
\hline Age & $78 \pm 3.44$ & $78 \pm 3.18$ & $78.5 \pm 3.68$ & 0.32 \\
\hline BMl & $26.51 \pm 3.90$ & $26.16 \pm 3.01$ & $26.87 \pm 4.59$ & 0.14 \\
\hline Weight & $74.01 \pm 12.63$ & $78.99 \pm 9.20$ & $69.18 \pm 13.13$ & $<0.001$ \\
\hline Height & $166.95 \pm 9.28$ & $174.77 \pm 6.91$ & $160,35 \pm 5.90$ & $<0.001$ \\
\hline $\operatorname{CRP}\left(\mathrm{mg} / \mathrm{l}^{\mathrm{a}}\right.$ & $5.1(11.13)$ & $5.25(12)$ & $45(18.9)$ & 0.82 \\
\hline Glucose (mmol/l) & $5.81 \pm 2.29$ & $5.86 \pm 2.10$ & $5.75 \pm 2.46$ & 0.68 \\
\hline $\mathrm{HDL}(\mathrm{mmol} / \mathrm{l})$ & $1.30 \pm 0.33$ & $1.19 \pm 0.26$ & $1.4 \pm 0.36$ & $<0.001$ \\
\hline LDL (mmol/l) & $3.18 \pm 1.0$ & $3.07 \pm 0.89$ & $3.29 \pm 1.08$ & 0.048 \\
\hline Creatinine $(\mu \mathrm{mol} / \mathrm{l})$ & $79.51 \pm 24.75$ & $88.07 \pm 24.88$ & $71.23 \pm 21.67$ & $<0.001$ \\
\hline GFR $\left(\mathrm{ml} / \mathrm{min} / 1.73 \mathrm{~m}^{2}\right)$ & $72.0 \pm 22.1$ & $74.5 \pm 19.5$ & $69.7 \pm 24.2$ & 0.057 \\
\hline \multicolumn{5}{|l|}{ History n (\%) } \\
\hline Smoking * & $27(8.6)$ & $22(14.2)$ & $5(3.1)$ & 0.005 \\
\hline Diabetes* ${ }^{* b}$ & $57(18.1)$ & $28(18.1)$ & $29(18.1)$ & 0.46 \\
\hline Hyperlipidemia * & $73(23.2)$ & $32(20.6)$ & $41(25.6)$ & 0.51 \\
\hline Angina pectoris * & $56(17.8)$ & $28(18.1)$ & $28(18.1)$ & 0.44 \\
\hline Myocardial infarction*3 & $27(8.6)$ & $19(12.3)$ & $8(5.0)$ & 0.021 \\
\hline Family history of $\mathrm{CV} * 4$ & $65(20.6)$ & $24(15.5)$ & $41(25.6)$ & 0.026 \\
\hline \multicolumn{5}{|l|}{ Medications, n (\%) } \\
\hline Statin treatment * & $69(21.9)$ & $32(20.6)$ & $37(23.1)$ & 0.40 \\
\hline Beta receptor blockers* & $114(34.9)$ & $54(34.8)$ & $60(37.5)$ & 0.63 \\
\hline ACE inhibitors* & $62(17.5)$ & $27(17.4)$ & 35 (21.9) & 0.15 \\
\hline Calcium channel blockers* & $51(16.2)$ & $27(17.4)$ & $24(15)$ & 0.65 \\
\hline Diuretics* & 115 (36.5) & $48(31)$ & 67 (41.9) & 0.045 \\
\hline
\end{tabular}

Data are the means \pm SD, frequencies and percentages* or as median and (range) ${ }^{\text {a }}$. HDL; high-density lipoprotein, LDL; low-density lipoprotein. ${ }^{b}$ Diagnosis alt. $>7$ mmol. ${ }^{3}$ ECG-verified. ${ }^{4}$ Family history of CV; Family history of cardiovascular disease.

Using the oscillometric technique, the SBP was higher among female subjects than among male subjects $(p=$ 0.003 ), and this difference was maintained after adjustments for age, HR and BSA $(p=0.006)$. Regarding diastolic blood pressure, no significant difference was found between sexes.

\section{FBN1}

Four alleles and eight combinations of FBN1 genotypes were identified $(1 / 2,1 / 4,2 / 2,2 / 3,2 / 4,3 / 3,3 / 4$, and $4 / 4)$, and the three most common genotypes $(2 / 2,2 / 3$ and $2 /$ 4) accounted for $79.4 \%$ of the population (males $75.4 \%$, females $83.1 \%$ ). Subsequent analysis was restricted to individuals with the three most common FBN1 genotypes $2 / 2,2 / 3$ and $2 / 4$ and were divided by sex. Data on pressure and arterial stiffness according to FBN1 genotype and sex are presented in Tables 3 and 4 . The frequencies of the genotypes were 2/2: 60.7\% (males), 61.7\% (females); 2/3: $14.5 \%$ (males), $13.5 \%$ (females); and 2/4: $34.2 \%$ (males), $24.8 \%$ (females).

There was a significant difference in HR between the three main genotypes in the male group. The $2 / 2$ genotype showed a significantly higher $\operatorname{HR}(p=0.036)$ than the $2 / 3$ and $2 / 4$ genotypes. After adjustments for age, the statistically significant difference compared to the $2 / 3$ and $2 / 4$ genotypes disappeared.

In the female group, the $2 / 3$ genotype showed a significantly higher AIx $(p=0.029)$ and SBP $(p=0.025)$ than the $2 / 2$ and $2 / 4$ genotypes. The difference in AIx between the genotypes was still significant after adjustment for age $(p=0.031)$. Regarding SBP, the $2 / 3$ genotype showed a slight increase in SBP after adjustment for age; however, no significant difference between the $2 / 3$ genotype and the $2 / 2$ or $2 / 4$ genotype was observed. Furthermore, the $2 / 3$ genotype in females had a significantly lower HR $(p=0.048)$ than the $2 / 2$ and $2 / 4$ genotypes.

\section{Discussion}

This study shows that elderly hypertensive females have a higher SBP, pMAP, cMAP, AIx, AG and TR than elderly hypertensive males. We have also shown a higher SBP and a higher AIx among hypertensive elderly females with the FBN1 2/3 genotype compared to hypertensive females with the two other common genotypes 
Table 2 Pressure and arterial stiffness related to sex differences

\begin{tabular}{|c|c|c|c|}
\hline & $\begin{array}{l}\text { Male } \\
n=155\end{array}$ & $\begin{array}{l}\text { Female } \\
n=160\end{array}$ & $p$-value \\
\hline pMAP (mmHg) & $101.55 \pm 10.58$ & $107.19 \pm 13.50$ & 0.008 \\
\hline $\mathrm{cSBP}(\mathrm{mmHg})$ & $139.22 \pm 16.86$ & $148.09 \pm 20.06$ & $<0.001$ \\
\hline $\mathrm{cDBP}(\mathrm{mmHg})$ & $77.65 \pm 9.52$ & $79.16 \pm 11.22$ & 0.33 \\
\hline $\mathrm{cPP}(\mathrm{mmHg})$ & $61.56 \pm 15.22$ & $68.93 \pm 17.03$ & 0.035 \\
\hline cMAP $(\mathrm{mmHg})$ & $101.56 \pm 10.58$ & $107.19 \pm 13.50$ & 0.008 \\
\hline Alx (\%) & $32.52 \pm 8.73$ & $36.04 \pm 9.22$ & $<0.001$ \\
\hline Al hr75 (\%) & $26.18 \pm 7.39$ & $32.73 \pm 6.91$ & $<0.001$ \\
\hline HR (beat/min) & $62.0 \pm 11.38$ & $68.06 \pm 12.01$ & $<0.001$ \\
\hline TR time $(\mathrm{s})$ & $133.26 \pm 10.29$ & $127.03 \pm 9.29$ & $<0.001$ \\
\hline AG (mmHg) & $20.45 \pm 9.37$ & $25.50 \pm 10.35$ & $<0.001$ \\
\hline SBP right $(\mathrm{mmHg})$ & $162.13 \pm 19.14$ & $169.57 \pm 23.51$ & 0.004 \\
\hline SBP left (mmHg) & $158.19 \pm 16.76$ & $165.18 \pm 20.40$ & 0.002 \\
\hline DBP right $(\mathrm{mmHg})$ & $80.31 \pm 9.58$ & $80.38 \pm 11.27$ & 0.91 \\
\hline DBP left (mmHg) & $79.38 \pm 9.36$ & $79.10 \pm 11.06$ & 0.67 \\
\hline $\mathrm{ABPI}$ right $(\mathrm{mmHg})$ & $1.067 \pm 0.25$ & $1.03 \pm 0.19$ & 0.57 \\
\hline ABPI left (mmHg) & $1.05 \pm 0.22$ & $1.02 \pm 0.18$ & 0.42 \\
\hline
\end{tabular}

All data are presented as the means \pm SDs. $p M A P$ Peripheral mean arterial pressure, $C S B P$ Central systolic blood pressure, CDBP Central diastolic blood pressure, $C P P$ Central pulse pressure, $C M A P$ Central mean arterial pressure, $A l x$ Augmentation index, Al hr75 Augmentation index heartrate 75, HR Heartrate, TR time Transistor time, AG Augmentation. Pressure: SBP Systolic blood pressure, $D B P$ Diastolic blood pressure, $A B P I$ Ankle brachial pressure index.
(2/2 and 2/4). Small but not statistical significantly differences in AIx between the FBN1 genotypes were also seen in male.

Increased arterial stiffness results in elevated systolic blood pressure, which is a prognostic indicator of future cardiovascular events [23, 24]. However, the Framingham study showed an increase in the incidence of cardiovascular diseases in females with age, and the cardiovascular incidence seems to be higher after menopause [25]. The lower level of estrogen in postmenopausal women could be the main reason for the increased risk of cardiovascular diseases [26, 27]. Many postmenopausal females are treated with hormone replacement therapy (HRT), and Mueck et al. found that both normotensive and hypertensive postmenopausal women run a very low risk of blood pressure increase during HRT [28].

Increases in SBP, cSBP, central and peripheral MAP, and $\mathrm{CPP}$ were observed in the hypertensive elderly females of our study compared to males, and these findings are in accordance with those of previous reports [29-31]. We used an oscillometric technique to measure brachial blood pressure, and a noninvasive tonometric system was used to analyze the pulse wave of the radial artery. Furthermore, when blood pressure was adjusted for age, HR and BSA, the differences between the sexes increased. Goto et al. (2013) used invasive measurements of blood pressure and observed the same trend in a large cohort, with a higher SBP and AIx $(p=0.048)$ among

Table 3 Pressure and arterial stiffness according to FBN1 genotype in males

\begin{tabular}{|c|c|c|c|c|}
\hline & 2/2 genotype & 2/3 genotype & 2/4 genotype & \\
\hline & $n=71$ & $n=14$ & $n=40$ & $p$-value \\
\hline pMAP (mmHg) & $102.4 \pm 10.5$ & $102.6 \pm 15.5$ & $100.3 \pm 10.0$ & 0.23 \\
\hline $\mathrm{cSBP}(\mathrm{mmHg})$ & $139.6 \pm 18$ & $137.1 \pm 23.3$ & $138.3 \pm 15.2$ & 0.83 \\
\hline cDBP $(\mathrm{mmHg})$ & $78.2 \pm 9.1$ & $79.5 \pm 13$ & $77.1 \pm 9.4$ & 0.29 \\
\hline $\mathrm{cPP}(\mathrm{mmHg})$ & $61.4 \pm 16.7$ & $57.6 \pm 16.3$ & $61.2 \pm 12.8$ & 0.67 \\
\hline cMAP (mmHg) & $102.4 \pm 10.5$ & $102.6 \pm 15.9$ & $100.3 \pm 9.9$ & 0.60 \\
\hline Alx (\%) & $30.22 \pm 9.47$ & $34.11 \pm 9.28$ & $33.70 \pm 7.71$ & 0.052 \\
\hline Al hr75 (\%) & $25.8 \pm 8.0$ & $28.3 \pm 6.6$ & $26.8 \pm 6.6$ & 0.52 \\
\hline HR (beats/min) & $66.0 \pm 11.6$ & $62.8 \pm 10.8$ & $60.5 \pm 9.8$ & 0.036 \\
\hline TR time (s) & $132.9 \pm 9.9$ & $132.4 \pm 8.7$ & $131.9 \pm 10.6$ & 0.87 \\
\hline $\mathrm{AG}(\mathrm{mmHg})$ & $19.5 \pm 9.9$ & $20.7 \pm 10.2$ & $21.2 \pm 7.9$ & 0.85 \\
\hline SBP right (mmHg) & $164.7 \pm 20.5$ & $158.0 \pm 23.1$ & $159.8 \pm 17.4$ & 0.42 \\
\hline SBP left $(\mathrm{mmHg})$ & $159.1 \pm 19.1$ & $155.9 \pm 18.6$ & $157.6 \pm 14.1$ & 0.87 \\
\hline DBP right $(\mathrm{mmHg})$ & $80.9 \pm 9.7$ & $79.8 \pm 8.37$ & $79.4 \pm 10.5$ & 0.94 \\
\hline DBP left (mmHg) & $79.8 \pm 8.8$ & $81.5 \pm 11.8$ & $79.7 \pm 9.32$ & 0.67 \\
\hline $\mathrm{ABPI}$ right $(\mathrm{mmHg})$ & $1.0 \pm 0.3$ & $1.1 \pm 0.2$ & $1.1 \pm 0.2$ & 0.64 \\
\hline ABPI left (mmHg) & $1.0 \pm 0.2$ & $1.1 \pm 0.2$ & $1.0 \pm 0.3$ & 0.82 \\
\hline
\end{tabular}

All data are presented as the means \pm SDs. $p M A P$ Peripheral mean arterial pressure, $C S B P$ Central systolic blood pressure, $C D B P$ Central diastolic blood pressure, $C P P$ Central pulse pressure, CMAP Central mean arterial pressure, Alx Augmentation index, Al hr75 Augmentation index heartrate 75, HR Heartrate, $T R$ time Transistor time, $A G$ Augmentation. Pressure: SBP Systolic blood pressure, DBP Diastolic blood pressure, ABPI Ankle brachial pressure index. 
Table 4 Pressure and arterial stiffness according to FBN1 genotype in females

\begin{tabular}{|c|c|c|c|c|}
\hline & 2/2 genotype & 2/3 genotype & 2/4 genotype & \\
\hline & $n=82$ & $n=18$ & $n=33$ & $p$-value \\
\hline pMAP (mmHg) & $103.8 \pm 14.1$ & $109.6 \pm 11.6$ & $106.7 \pm 14.1$ & 0.39 \\
\hline cSBP (mmHg) & $139.5 \pm 18$ & $137.1 \pm 23.3$ & $138.3 \pm 15.2$ & 0.36 \\
\hline cDBP $(\mathrm{mmHg})$ & $78.7 \pm 11.1$ & $81.1 \pm 10.1$ & $79.3 \pm 12.4$ & 0.29 \\
\hline $\mathrm{cPP}(\mathrm{mmHg})$ & $68.7 \pm 16.4$ & $71.1 \pm 19.8$ & $67.1 \pm 15.8$ & 0.88 \\
\hline CMAP $(\mathrm{mmHg})$ & $106.8 \pm 17.1$ & $109.6 \pm 11.6$ & $106.7 \pm 14.1$ & 0.39 \\
\hline Alx (\%) & $35.03 \pm 9.39$ & $39.86 \pm 8.93$ & $35.80 \pm 8.95$ & 0.047 \\
\hline Al hr75 (\%) & $25.8 \pm 6.6$ & $28.3 \pm 6.6$ & $26.8 \pm 6.6$ & 0.72 \\
\hline HR (beat/min) & $69.9 \pm 12.4$ & $62.6 \pm 10.4$ & $67.8 \pm 11.3$ & 0.048 \\
\hline TR time $(s)$ & $127.0 \pm 9.1$ & $126.0 \pm 10.6$ & $127.1 \pm 8.2$ & 0.49 \\
\hline $\mathrm{AG}(\mathrm{mmHg})$ & $24.7 \pm 10.3$ & $29.1 \pm 12.4$ & $24.7 \pm 9.9$ & 0.18 \\
\hline SBP right $(\mathrm{mmHg})$ & $168.9 \pm 23.4$ & $178.3 \pm 25.6$ & $169.9 \pm 23.4$ & 0.14 \\
\hline SBP left (mmHg) & $164.1 \pm 19.6$ & $174.6 \pm 23.1$ & $161.5 \pm 17.4$ & 0.049 \\
\hline DBP right $(\mathrm{mmHg})$ & $80.4 \pm 11.32$ & $80.7 \pm 12.5$ & $79.8 \pm 10.1$ & 0.94 \\
\hline DBP left (mmHg) & $79.5 \pm 10.8$ & $80.0 \pm 12.5$ & $78.3 \pm 11.4$ & 0.84 \\
\hline $\mathrm{ABPI}$ right $(\mathrm{mmHg})$ & $1.0 \pm 0.2$ & $1.0 \pm 0.1$ & $1.0 \pm 0.2$ & 0.41 \\
\hline ABPI left $(\mathrm{mmHg})$ & $1.0 \pm 0.2$ & $1.1 \pm 0.1$ & $1.0 \pm 1.2$ & 0.48 \\
\hline
\end{tabular}

All data are presented as the means \pm SDs. $p M A P$ Peripheral mean arterial pressure, $C S B P$ Central systolic blood pressure, $C D B P$ Central diastolic blood pressure, $C P P$ Central pulse pressure, $C M A P$ Central mean arterial pressure, Alx Augmentation index, Al hr75 Augmentation index heartrate 75 , HR Heartrate, TR time Transistor time, AG Augmentation. Pressure: SBP Systolic blood pressure, DBP Diastolic blood pressure, ABPI Ankle brachial pressure index

elderly females than among elderly males, similar to our findings (Table III) [31].

Elderly hypertensive females seem to have higher SBP than males; thus, it is important to discuss the differences between sexes regarding the treatment of hypertension. Ong et al. (2008) studied sex differences in blood pressure rate control among Americans with diagnosed hypertension and showed that blood pressure measurement control rates were not significantly lower among females than among males [32]. The guidelines recommend that hypertensive males and females should be treated with the same approach, and evidence shows that females show a benefit from antihypertensive treatment that is similar to that of males. The $2018 \mathrm{ESH} / \mathrm{ESC}$ Guidelines recommend the use of antihypertensive drugs by all patients diagnosed with grade 1 hypertension [33]. The use of antihypertension drugs may affect the arterial impedance. In the present study we found a significance difference between sexes in diuretic treatment. However, diuretics seem to have no beneficial effect on pulsatile hemodynamics and a neutral effect on AIx and PWV. Beta-Blockers, ACE-inhibitors and Calcium channel blockers have been seen to improves arterial stiffness, but there was no significance difference between sexes in treatment with these medications [34].

FBN1 is a glycoprotein that forms FBN1-rich microfibrils and functions as a skeleton for the deposition of tropoelastin, forming elastic fibers in the arterial wall. FBN1 might affect the maintenance of the integrity of the arterial wall of central arteries, and FBN1 is considered to be a candidate gene of arterial stiffness [13, 35]. The different FBN1 genotypes have been studied in several populations, and the frequencies of these genotypes in our present study are in accordance with what others have reported previously among healthy subjects $[17,18$, 36], AAA-patients [37], patients with coronary artery diseases [16] and middle-aged subjects [22]. The increased prevalence of the FBN1 2/3 genotype in this population may explain the impact on the structure of the aortic wall, as shown by increased aortic stiffness.

The females in the present study with the FBN1 2/3 genotype had a higher AIx and SBP than those with the other common genotypes, namely, $2 / 2$ and $2 / 4$. These differences were not observed in males. One causative explanation of the observed sex difference could be the fact that hypertensive males with high levels of and/or multiple risk factors for cardiovascular diseases already have died in cardiovascular events due to the early onset of cardiovascular morbidity in males [3, 4]. Arterial stiffness is an independent predictor of cardiovascular morbidity and mortality, and AIx is an indirect measure of arterial stiffness $[3,4]$. Several studies have found an association between the FBN1 2/3 genotype and arterial stiffness in males $[15,16]$; however, we observed an association between higher AIx and FBN1 2/3 in only elderly hypertensive females and not in elderly hypertensive males. Furthermore, after adjustment for age, the increase in AIx was reduced, although it still reached 
significance. In studies of both sexes (healthy individuals), no associations between the FBN1 2/3 genotype and arterial stiffness were observed [18]. Compared to that of the previously published work, our population consisted of hypertensive elderly patients, and this could be a possible explanation for the difference in findings. Arterial aging is associated with a decreased amount of elastin in the large elastic arteries and affects arterial stiffness. As arterial stiffness is an independent predictor of cardiovascular morbidity and mortality, some elderly hypertensive patients with high levels of and/or multiple risk factors for cardiovascular diseases may have already died due to cardiovascular events. Thus, it must be considered that the differences between the genotypes may be larger in a younger population.

\section{Limitations}

The interpretation of the findings from the present study has limitations. First, the different number of subjects in each FBN1 genotype group (Tables 3 and 4) could influence the results due to limited numbers of subjects in the FBN1 2/3 genotype group. Second, the PWA was calculated from measurements of the radial artery and was performed according to the manufacturer's recommendations and guidelines regarding measurements of PWA [38]. However, peripheral blood pressure may not accurately reflect actual aortic PWV. Third, our analysis follows a cross-sectional design and no data on outcomes are reported; therefore, no direct cause-and-effect associations can be derived from this study design. A fourth limitation is that no lifestyle items, medical history of stroke and information about diabetic microvascular complications were included. Our participants were old and the duration of diabetes and HbAlc was not included in the study. Finally, it is a limitation that we do not have data about left ventricular ejection fraction and valvular heart disease. More studies are needed to define the possible effect that the FBN1 2/3 genotype may have on cardiovascular morbidity and mortality.

\section{Conclusion}

In conclusion, the findings of our study indicate that hypertensive females in an elderly population have increased SBP and arterial stiffness compared to males. These findings also indicate that elderly females with FBN1 2/3 have increased arterial stiffness compared to hypertensive elderly females with FBN1 $2 / 2$ or FBN1 2/ 4. Therefore, these findings may be used to design potential therapeutic targets to reduce hypertension in females with the FBN1 2/3 genotype. Measurement of PWV may be a useful tool in clinical practice, especially in female, to select subjects at high risk of developing cardiovascular diseases [39]. However, further studies are needed to confirm our results.

\section{Abbreviations}

AAA: Abdominal aortic aneurysm; ABPI: Ankle brachial pressure index AugP: Augmentation pressure; Al hr75: Augmentation index heartrate 75; Alx: Augmentation index; AG: Augmentation pressure; BMl: Body mass index; BSA: Body surface area; BP: Base pair; cMAP: Central mean arterial pressure; CPP: Central pulse pressure; CSBP: Central systolic blood pressure;

DBP: Diastolic blood pressure; ECG: Electrocardiographically; FBN1: Fibrillin-1; HDL: High-density lipoprotein; HR: Heart rate; HRT: Hormone replace therapy; LDL: Low-density lipoprotein; MFS: Marfan syndrome; MI: Myocardial infarction; PCR: Polymerase chain reaction; PMAP: Peripheral mean arterial pressure; PP: Pulse pressure; PWA: Pulse wave analysis; PWV: Pulse wave velocity; SBP: Systolic blood pressure; TR time: Transistor time; VNTR: Variable number of tandem repeat

\section{Acknowledgements}

Not Applicable.

\section{Authors' contributions}

RDB, UA and UD designed the research. RDB recruit the subjects. IAM and $\mathrm{RDB}$ analyzed and interpreted the data; IAM performed the statistical analysis and wrote the first draft of the manuscript. PB and RDB critically revised the manuscript for key intellectual content. All authors revised the manuscript for important intellectual content and all authors read and approved the final version. Each author participated sufficiently in the work.

\section{Funding}

This study was supported by grants from The Swedish Research Council (\#12661); Swedish Heart and Lung Foundation (\#20130650); Futurum - the Academy for Healthcare, County Council, Jönköping, Sweden (\#259701); and King Gustav V and Queen Victoria's Foundation and Medical Research Council of Southeast Sweden (FORSS) (\#34931). None of the grant providers influenced the results of the current study. The funders had no role in study design, data collection and analysis, decision to publish, or preparation of the manuscript. Open access funding provided by Jönköping University.

\section{Availability of data and materials}

The datasets used and/or analyzed during the current study are available from the corresponding author on reasonable request.

\section{Ethics approval and consent to participate}

The study protocol was approved by the Regional Ethical Review Board of Linköping, Sweden (Dnr 95044) and was conducted in accordance with the principles stated in the Declaration of Helsinki. All participants provided informed written consent.

\section{Consent for publication \\ Not applicable.}

\section{Competing interests}

Ida Åström Malm, Urban Alehagen, Ulf Dahlström, Peter Blomstrand and Rachel De Basso declared they do not have anything to disclose regarding conflicts of interest with respect to this manuscript. Ulf Dahlström has research grants from AstraZeneca, Novartis and Amgen that are unrelated to the present work and therefore had no influence on the present study.

\section{Author details \\ ${ }^{1}$ School of Health and Welfare, Jönköping University, Jönköping, Sweden. ${ }^{2}$ Department of Medical and Health Sciences, Linköping University, Linköping, Sweden. ${ }^{3}$ Department of Clinical Physiology, County Hospital Ryhov, Jönköping, Sweden. ${ }^{4}$ Department of Cardiology Linköping University, Linköping, Sweden.}

Received: 16 January 2020 Accepted: 29 March 2020 Published online: 17 April 2020

\section{References}

1. Safar ME. Arterial stiffness as a risk factor for clinical hypertension. Nat Rev Cardiol. 2018;15(2):97-105

2. Whelton PK. The Elusiveness of Population-Wide High Blood Pressure Control. Annu Rev Public Health. 2015;36(1):109-30. 
3. Laurent S, Boutouyrie P, Asmar R, Gautier I, Laloux B, Guize L, et al. Aortic stiffness is an independent predictor of all-cause and cardiovascular mortality in hypertensive patients. Hypertension. 2001;37(5):1236-41.

4. Boutouyrie P, Tropeano Al, Asmar R, Gautier I, Benetos A, Lacolley P, et al. Aortic stiffness is an independent predictor of primary coronary events in hypertensive patients: a longitudinal study. Hypertension. 2002;39(1):10-5.

5. Giannattasio C, Failla M, Grappiolo A, Gamba PL, Paleari F, Mancia G. Progression of large artery structural and functional alterations in type I diabetes. Diabetologia. 2001;44(2):203-8.

6. Lakatta EG. Arterial pressure and aging. Int J Cardiol. 1989;25(Suppl 1):S81-9.

7. Länne T, Sonesson B, Bergqvist D, Bengtsson H, Gustafsson D. Diameter and compliance in the male human abdominal aorta: influence of age and aortic aneurysm. Eur J Vasc Surg. 1992;6(2):178-84.

8. Länne T, Sandgren T, Sonesson B. A dynamic view on the diameter of abdominal aortic aneurysms. Eur J Vasc Endovasc Surg. 1998;15(4):308-12.

9. Lee HY, Oh BH. Aging and arterial stiffness. Circ J. 2010;74(11):2257-62

10. Goto T, Baba T, Ito A, Maekawa K, Koshiji T. Gender differences in stroke risk among the elderly after coronary artery surgery. Anesth Analg. 2007;104(5): 1016-22 tables of contents.

11. Wright JD, Hughes JP, Ostchega Y, Yoon SS, Nwankwo T. Mean systolic and diastolic blood pressure in adults aged 18 and over in the United States, 2001-2008. Natl Health Stat Report. 2011;35:1-22 4.

12. Ninios I, Ninios V, Lazaridou F, Dimitriadis K, Kerasidou O, Louridas G. Gender-specific differences in hypertension prevalence, treatment, control, and associated conditions among the elderly: data from a Greek population. Clin Exp Hypertens. 2008;30(5):327-37.

13. Kielty CM, Sherratt MJ, Shuttleworth CA. Elastic fibres. J Cell Sci. 2002;115(Pt 14):2817-28.

14. Nichols WW. McDonald's blood flow in arteries [Elektronisk resurs] : theoretic, experimental, and clinical principles. London: Hodder Arnold; 2011.

15. Powell JT, MacSweeney ST, Greenhalgh RM, Turner RJ, Henney AM. Interaction between fibrillin genotype and blood pressure and the development of aneurysmal disease. Ann N Y Acad Sci. 1996;800:198-207.

16. Medley TL, Cole TJ, Gatzka CD, Wang WY, Dart AM, Kingwell BA. Fibrillin-1 genotype is associated with aortic stiffness and disease severity in patients with coronary artery disease. Circulation. 2002;105(7):810-5.

17. Powell JT, Turner RJ, Sian M, Debasso R, Lanne T. Influence of fibrillin-1 genotype on the aortic stiffness in men. J Appl Physiol. 2005;99(3):1036-40.

18. Yasmin O'SKM, McEniery CM, Cockcroft JR, Wilkinson IB. Genetic variation in fibrillin-1 gene is not associated with arterial stiffness in apparently healthy individuals. J Hypertens. 2006;24(3):499-502.

19. Alehagen U, Goetze JP, Dahlstrom U. Reference intervals and decision limits for B-type natriuretic peptide (BNP) and its precursor (Nt-proBNP) in the elderly. Clin Chim Acta. 2007;382(1-2):8-14.

20. Björck HM, Eriksson P, Alehagen U, Basso RD, Ljungberg LU, Persson K, et al. Gender-specific Association of the Plasminogen Activator Inhibitor-1 4G/5G polymorphism with central arterial blood pressure. Am J Hypertens. 2011; 24(7):802-8.

21. De Basso R. Influence of genetics and mechanical properties on large arteries in man [doctoral thesis, comprehensive summary]. Linköping: Linköping University Electronic Press; 2013.

22. De Basso R, Hedblad B, Carlson J, Persson M, Ostling G, Lanne T. Increased carotid plaque burden in men with the fibrillin-1 2/3 genotype. Clin Exp Pharmacol Physiol. 2014;41(9):637-42.

23. Laurent S, Cockcroft J, Van Bortel L, Boutouyrie P, Giannattasio C, Hayoz D, et al. Expert consensus document on arterial stiffness: methodological issues and clinical applications. Eur Heart J. 2006;27(21):2588-605.

24. Sun Z. Aging, arterial stiffness, and hypertension. Hypertension. 2015;65(2): 252-6.

25. Kannel WB. The Framingham study: historical insight on the impact of cardiovascular risk factors in men versus women. J Gend Specif Med. 2002; 5(2):27-37.

26. Appiah D, Schreiner PJ, Demerath EW, Loehr LR, Chang PP, Folsom AR. Association of age at menopause with incident heart failure: a prospective cohort study and meta-analysis. J Am Heart Assoc. 2016:5(8):e003769.

27. Ratiani L, Khorava M, Dgebuadze M, Zhvania N, Sanikidze T. The role of estrogens in pathogenesis of age-related arterial hypertension. Georgian Med News. 2012(208-209):71-6.

28. Mueck $A O$, Seeger $H$. Effect of hormone therapy on BP in normotensive and hypertensive postmenopausal women. Maturitas. 2004;49(3):189-203.
29. Modena MG. Hypertension in postmenopausal women: how to approach hypertension in menopause. High Blood Press Cardiovasc Prev. 2014;21(3): 201-4.

30. Su D, Song A, Yan B, Guo Q, Gao Y, Zhou Y, et al. Circadian blood pressure variations in postmenopausal females with hypertension. Int Heart J. 2018; 59(2):361-6.

31. Goto T, Ohte N, Fukuta H, Wakami K, Tani T, Kimura G. Relationship between effective arterial elastance, total vascular resistance, and augmentation index at the ascending aorta and left ventricular diastolic function in older women. Circ J. 2013;77(1):123-9.

32. Ong KL, Tso AW, Lam KS, Cheung BM. Gender difference in blood pressure control and cardiovascular risk factors in Americans with diagnosed hypertension. Hypertension. 2008;51(4):1142-8.

33. Zanchetti A, Dominiczak A, Coca A, Tsioufis C, Clement DL, Agabiti Rosei E, et al. 2018 ESC/ESH guidelines for the management of arterial hypertension. Eur Heart J. 2018;39(33):3021-104.

34. Janić M, Lunder M, Sabovič M. Arterial stiffness and cardiovascular therapy. Biomed Res Int. 2014;2014:621437.

35. Sherratt MJ, Wess TJ, Baldock C, Ashworth J, Purslow PP, Shuttleworth CA, et al. Fibrillin-rich microfibrils of the extracellular matrix: ultrastructure and assembly. Micron. 2001;32(2):185-200.

36. Powell JT, Turner RJ, Henney AM, Miller GJ, Humphries SE. An association between arterial pulse pressure and variation in the fibrillin-1 gene. Heart. 1997;78(4):396-8.

37. MacSweeney ST, Skidmore C, Turner RJ, Sian M, Brown L, Henney AM, et al. Unravelling the familial tendency to aneurysmal disease: popliteal aneurysm hypertension and fibrillin genotype. Eur J Vasc Endovasc Surg. 1996;12(2): 162-6.

38. Herbert A. Collaboration oboTRVfAM, Cruickshank JK, collaboration oboTRVFAM, Laurent S, collaboration oboTRVfAM, et al. establishing reference values for central blood pressure and its amplification in a general healthy population and according to cardiovascular risk factors. Eur Heart J. 2014;35(44):3122-33.

39. Kim H-L, Kim S-H. Pulse Wave Velocity in Atherosclerosis. Front Cardiovasc Med. 2019;6:41.

\section{Publisher's Note}

Springer Nature remains neutral with regard to jurisdictional claims in published maps and institutional affiliations.

Ready to submit your research? Choose BMC and benefit from

- fast, convenient online submission

- thorough peer review by experienced researchers in your field

- rapid publication on acceptance

- support for research data, including large and complex data types

- gold Open Access which fosters wider collaboration and increased citations

- maximum visibility for your research: over $100 \mathrm{M}$ website views per year

At $\mathrm{BMC}$, research is always in progress.

Learn more biomedcentral.com/submissions 